\title{
PRINCIPAIS PLANTAS TÓXICAS CAUSADORAS DE MORTE SÚBI- TA EM BOVINOS NO ESTADO DO ESPÍRITO SANTO - BRASIL
}

\author{
PRINCIPAL TOXICANT PLANTS THAT CAUSE SUDDEN DEATH IN BOVINE IN ESPÍRITO \\ SANTO STATE - BRAZIL
}

\begin{abstract}
Carvalho, G.D.*1, Nunes, L.C. ${ }^{2}$, Bragança, H.B.N. ${ }^{3}$ e Porfírio, L.C. ${ }^{2}$
'Departamento de Medicina Veterinária. Faculdade de Ciências Biológicas e da Saúde. UNIVIÇOSA. Av. Maria de Paula Santana, no 740 - Bairro Silvestre. Viçosa, Minas Gerais, Brasil. 36570-000. *gabriel@univicosa.com.br

${ }^{2}$ Departamento de Medicina Veterinária. Centro de Ciências Agrárias. Universidade Federal do Espírito Santo (UFES). Alegre, ES. Brasil.

${ }^{3}$ Departamento de Fitotecnia. Centro de Ciências Agrárias. Universidade Federal do Espírito Santo (UFES). Alegre, ES. Brasil
\end{abstract}

\section{Palavras chave adicionais}

Intoxicação. Palicourea marcgravii. Mascagnia rigida. Tetrapterys acutifolia. Oxypetalum banksii.

\section{RESUMO}

No Brasil é muito freqüente a ocorrência de morte súbita em bovinos, causada por ingestão de plantas tóxicas. Estas mortes repentinas em geral se manifestam sem sinais clínicos prévios e ausência de achados necroscópicos significativos, promovendo perdas econômicas difíceis de serem estimadas. O desconhecimento das espécies vegetais tóxicas é apontado como o principal fator para ocorrência desses acidentes, desse modo, a melhor forma de prevenir é o conhecimento e a divulgação a respeito do assunto. Neste contexto, este trabalho expõe as principais plantas tóxicas relatadas, até o momento, como causadoras de morte súbita em bovinos no Estado do Espírito Santo (Palicourea marcgravii, Mascagnia rigida, Tetrapterys acutifolia e Oxypetalum banksii), tendo em vista o grande número de casos de intoxicação ocorridos nessa região.

\section{SUMMARY}

In Brazil is very frequent the occurrence of sudden death in bovine, caused by the ingestion of toxicant plants. Those sudden deaths in general show none previous clinical signs and absence of significant post mortem discoveries, promoting

\section{Additional KeYWORDS}

Intoxication. Palicourea marcgravii. Mascagnia rigida. Tetrapterys acutifolia. Oxypetalum banksii.

economical losses with difficulties to be considered. The ignorance of the toxicant vegetable species is pointed as the principal factor for occurrence of those accidents, in that way, the best form to prevent this is the knowledge and the popularization regarding about the subject. In that context, this work exposes the principal toxicant plants that cause sudden death in bovine in Espírito Santo State (Palicourea marcgravii, Mascagnia rigida, Tetrapterys acutifolia and Oxypetalum banksii), tends in view the great number of intoxication cases that happened in this region.

\section{INTRODUÇÃO}

No Brasil é muito freqüente a ocorrência de morte súbita nos bovinos, causada por ingestão de plantas tóxicas. Essas mortes repentinas em geral se manifestam sem sinais clínicos prévios e ausência, na necropsia, de achados macroscópicos significativos (Tokarnia e Döbereiner, 1986). As intoxicações por plantas em animais de produção, no Brasil são conhecidas desde que os pioneiros espanhóis e portugueses introduziram as primeiras cabeças de gado 
em pastagens naturais da região. Segundo Riet-Correa et al. (1993) as perdas econômicas ocasionadas pelas intoxicações por plantas podem ser definidas como diretas ou indiretas. As perdas diretas são causadas pelas mortes de animais, diminuição dos índices reprodutivos (abortos, infertilidade, malformações), redução da produtividade nos animais sobreviventes e outras alterações devidas a doenças transitórias, enfermidades subclínicas com diminuição da produção de leite, carne ou lã, e aumento à susceptibilidade a outras doenças devido à depressão imunológica. As perdas indiretas incluem os custos de controlar as plantas tóxicas nas pastagens, as medidas de manejo para evitar as intoxicações como a utilização de cercas e o pastoreio alternativo, a redução do valor da forragem devido ao atraso na sua utilização, a redução do valor da terra, a compra de gado para substituir os animais mortos, e os gastos associados ao diagnóstico das intoxicações e ao tratamento dos animais afetados. Riet-Correa e Medeiros (2000) afirmaram que as perdas econômicas causadas pelas intoxicações por plantas são difíceis de ser estimadas porque não existem dados confiáveis sobre todos esses componentes, no entanto, essas perdas são fáceis de determinar quando dispomos de dados sobre a freqüência das causas de mortes dos animais numa determinada região.

Algumas mortes nos rebanhos bovinos são atribuídas a doenças, como carbúnculo hemático, ou confundidas com picadas de serpentes venenosas, quando o verdadeiro motivo é a ingestão de plantas tóxicas pelos animais (Bertinato, 1979; Tokarnia et al., 1979). No Brasil, as causas mais freqüentes de mortes súbitas são as intoxicações por plantas, sendo que, até o momento são conhecidas 12 espécies que causam esta síndrome: Palicourea marcgravii (Pacheco e Carneiro, 1932; Döbereiner e Tokarnia, 1959), P. grandiflora (Tokarnia et al., 1981), P.juruana (Tokarnia e Döbereiner, 1982) e P. aeneofusca (Tokarnia et al., 1983) da família Rubiaceae; Arrabidaea japurensis
(Tokarnia e Döbereiner, 1981), A. bilabiata (Döbereiner et al., 1983) e Pseudocalymma elegans (Mello e Fernandes, 1941; Tokarnia et al., 1969) da família Bignoniaceae; Mascagnia rigida (Tokarnia et al., 1961), M. aff. rigida (Tokarnia et al., 1985), $M$. pubiflora (Fernandes e Macruz, 1964), M. elegans (Couceiro et al., 1976) e Mascagnia sp (Gava et al., 1997) da família Malpighiaceae.

Na região sul do Estado do Espírito Santo a dificuldade de diagnóstico de intoxicação por plantas é notória, bem como a falta de registros do número de óbitos de animais, aliada a crendices muito presentes na cultura regional. Este trabalho expõe as principais plantas incriminadas de serem as causadoras de "morte súbita" em bovinos no Estado do Espírito Santo. As plantas Palicourea marcgravii, Mascagnia rígida, Tetrapterys acutifolia e Oxypetalum banksii são relatadas como as de maior ocorrência nessa região.

\section{PaLICOUREA MARCGRAVII}

A Palicourea marcgravii St. Hil. é a planta tóxica mais importante do grupo das plantas que causam "morte súbita" para bovinos no Brasil, devido a sua extensa distribuição, boa palatabilidade, alta toxidez e efeito acumulativo (Tokarnia et al., 1979). Pertence à família Rubiaceae, a mesma do café, a $P$. marcgravii é conhecida popularmente como "erva de rato", "cafezinho", "café bravo", "erva café", "roxa", "roxinha", "roxona", "vick" (Freitas et al., 1995; Tokarnia et al., 2000), "cotó-cotó" e "tangaráaçu" (Schvartsman, 1979; Schvartsman, 1992).

O nome popular "erva de rato", primitivamente reservado para uma ou duas Rubiáceas, tornou-se, porém genérico, próprio para definir mais a ação tóxica do que a espécie vegetal. Ele se aplica a várias Rubiáceas de gêneros diversos e também a Asclepiadáceas e Apocináceas que vitimam o gado e outros animais. As "ervas de rato" verdadeiras são todas Rubiáceas, sendo que a $P$. marcgravii têm o efeito mais temível e os casos de intoxicação do gado por esta 


\section{PLANTASTÓXICAS CAUSADORAS DE MORTE SÚBITA EM BOVINOS}

planta é conhecida desde o século XVII (Hoehne, 1939). O nome "erva de rato", veio do uso popular dos frutos dessa planta para matar ratos, misturando-os com azeite e outros alimentos depois de bem triturados (Hoehne, 1939; Schvartsman, 1979; Schvartsman, 1992; Kissmann e Groth, 2000).

A $P$. marcgravii é uma planta bastante conhecida em todas as regiões do Brasil, especialmente na região sudeste. É a planta tóxica de distribuição geográfica mais ampla no Brasil, sendo encontrada em todo o país, com exceção do extremo sul e do sertão nordestino. Ocorre em terra firme, em áreas sombreadas das beiras de matas, capoeiras e em pastos recém-formados (Freitas et al., 1995; Kissmann e Groth, 2000). As matas hidrófilas são o seu "habitat", mas quando estas são derrubadas, a $P$. marcgravii pode permanecer nas capoeiras e nos matagais secundários, surgindo também nas serras, nos vales e nos terrenos férteis (Hoehne, 1939). A P. marcgravii não sobrevive durante muito tempo em pastagens limpas, onde fica exposta ao sol, ela precisa de sombra (Tokarnia et al., 2000).

A planta é reproduzida por semente. $\mathrm{Na}$ região Sudeste do Brasil a floração ocorre especialmente na primavera e no outono, com frutificação mais intensa nos meses de abril e maio. A P. marcgravii é um vegetal arbustivo ou subarbustivo, variando sua altura entre 0,5 a 4,0 metros, formando touceiras pelo brotamento de gemas na parte inferior do caule (Kissmann e Groth, 2000). $P$. marcgravii tem caule lenhoso e nodoso, o lenho é sempre muito quebradiço e seco (Hoehne, 1939), com ramos cilíndricos, flexuosos, geralmente de coloração purpurescente quando novos, glabros ou com pilosidade esparsa. As raízes da $P$. marcgravii são bem desenvolvidas e as folhas são opostas, curtamente pecioladas, guarnecidas por estípulas bipartidas com 24 milímetros de comprimento por 3-8 milímetros de largura. As lâminas, de lanceoladas a oblongo-lanceolares, com 5-10 centímetros de comprimento por 2-4 centímetros de largura, com base cuneada e ápice acuminado e margem reforçada. Com textura cartácea, esparsamente pubérulas nas nervuras na face dorsal, quando novas às vezes são violáceas na face dorsal. Quando amassadas as folhas exalam um odor de salicilato de metila, cheiro característico do BálsamoBengué (Kissmann e Groth, 2000).

Nos descampados, onde a planta recebe mais raios solares e é mais fustigada pelos ventos, as suas folhas se encrespam e, algumas vezes, mostram uma coloração levemente arroxeada. Nas extremidades dos ramos ficam as inflorescências, curtos panículos geralmente avermelhados ou alaranjados que sustentam as flores tubulosas, cuja parte externa é revestida de papilas flocosas (Hoehne, 1939). As panículas terminais apresentam 4-8 centímetros de comprimento, com pedúnculos e pedicelos alaranjados ou avermelhados. As flores possuem cálice curto com lobos cuneados, pubescentes, corola tubulosa com base glibosa, com 1,5-2,0 centímetros de comprimento por 3-4 milímetros de largura, de coloração amarela na base, sulferina no meio e rosada a púrpura no ápice, externamente pubescente a partir da porção mediana e internamente com um anel de pêlos. Estames com anteras brancas, inseridas na região mediana do tubo. Ovário ínfero, com óvulo fixado na base do lóculo, encimado por estigma arroxeado. Findas as flores formam-se os frutos, que são drupas globosas com dois pirênios monospérmicos plano-convexo, do lado ventral com profundo sulco mediano, com 3-5 milímetros de diâmetro. Cada fruto encerra duas sementes plano-convexas, com 3 milímetros de comprimento por 2 milímetros de largura (Kissmann e Groth, 2000).

A intoxicação provocada pela $P$. marcgravii, em condições naturais, tem sido relatada apenas em bovinos, mas sua toxicidade já foi experimentalmente demonstrada em caprinos (Pacheco e Carneiro, 1932; Tokarnia et al., 1991) e em ovinos (Tokarnia et al., 1986), coelhos 
(Pacheco e Carneiro, 1932; Peixoto et al., 1987; Tokarnia et al., 1994), cobaias, ratos (Pacheco e Carneiro, 1932) e eqüinos (Pacheco e Carneiro, 1932; Tokarnia et al., 1993). Experimentos realizados por Barbosa et al. (2003) concluíram que os búfalos são, aproximadamente, seis vezes mais resistentes à ação tóxica de $P$. marcgravii do que os bovinos.

Os acidentes ocorrem quando o gado penetra nas matas ou quando se derrubam as matas para a formação de pastos, ocorrendo assim uma grande proliferação e aumentando conseqüentemente os riscos de acidentes (Kissmann e Groth, 2000; Tokarnia et al., 2000).

A planta possui, aparentemente, boa palatabilidade, pois os bovinos a ingerem em qualquer época do ano, mesmo havendo forragem em abundância (Freitas et al., 1995; Tokarnia et al., 2000). Devido sua boa palatabilidade, alta toxidez e por possuir um efeito acumulativo basta existir pequenas quantidades da planta na região para que haja casos de intoxicação. Por isso, em todas as áreas onde ocorre P. marcgravii, morrem bovinos por ela intoxicados. Isto é tão constante, que pode-se concluir que, onde não há mortandades de bovinos por "morte súbita", não existe $P$. marcgravii (Tokarnia et al., 2000).

O princípio ativo tóxico da $P$. marcgravii foi indentificado por Oliveira (1963) e mais tarde comprovado por outros pesquisadores (Hall, 1972; Moraes, 1993). Trata-se do ácido monofluoracético, ou monofluoracetato, um dos venenos mais violentos que se conhece, ele interfere no metabolismo energético celular, inibindo o ciclo de Krebs (Tokarnia et al., 2000). O monofluoracetatoé uma substância que bloqueia a respiração celular ao inibir a enzima aconitato dehidrogenase (aconitase) do ciclo do ácido tricarboxílico (Sherley, 2004). Este princípio parece apresentar efeito acumulativo, conforme foi observado em bovinos (Pacheco e Carneiro, 1932; Costa et al., 1984) e em ovinos (Tokarnia et al., 1986), mas não em ratos (Górniak, 1988)

São tóxicos, especialmente, os frutos e as folhas, sendo que os frutos mostram-se sempre mais tóxicos do que as folhas e as flores (Hoehne, 1939; Kissmann e Groth, 2000), sendo eles letais na dose de 0,40 grama por quilo de peso vivo do animal $(0,4$ $\mathrm{g} / \mathrm{kg}$ ) (Hoehne, 1939). As folhas mostram toxicidade mesmo quando secas (Górniak et al., 1987). Para bovinos a dose letal está em torno de 1 grama de folha fresca por quilograma de peso vivo do animal $(1 \mathrm{~g} / \mathrm{kg})$ (Freitas et al., 1995), alguns autores citam ainda doses de 0,65 - 0,75 gramas de planta por quilo de peso vivo de animal $(0,65-0,75$ $\mathrm{g} / \mathrm{kg}$ ) (Kissmann e Groth, 2000) e 0,6 gramas de folhas frescas por quilograma de peso vivo do animal $(0,6 \mathrm{~g} / \mathrm{kg})$ (Tokarnia et al., 2000).

Os sintomas de intoxicação, nos bovinos, iniciam poucas horas após ser completada a ingestão da dose letal. A evolução da intoxicação é, geralmente, superaguda, sendo letal em alguns minutos (Górniak et al., 1987; Freitas et al., 1995). Os sintomas consistem em queda repentina do animal ao chão, sobrevindo a morte dentro de poucos minutos. Às vezes o animal, antes de cair, apresenta desequilíbrio do trem posterior, tremores musculares, respiração ofegante (Freitas et al., 1995), pulso venoso positivo, instabilidade, o animal deita ou cai em decúbito, realiza movimentos de pedalagem, mugidos e convulsão tônica (Tokarnia et al., 2000). Exercícios físicos, como andar ou correr, podem precipitar, ou mesmo provocar, os sintomas e a morte (Freitas et al., 1995; Tokarnia et al., 2000).

À necropsia, os achados macroscópicos são praticamente negativos ou poucos específicos, podendo às vezes ser observadas hemorragias no epicárdio e congestão dos pulmões e da mucosa do intestino delgado. Algumas leves alterações de natureza regressiva e circulatória, não muito constantes, podem ser observadas no coração, rim e fígado (Tokarnia et al., 2000). Microscopicamente pode ser observada 


\section{PLANTASTÓXICAS CAUSADORAS DE MORTE SÚBITA EM BOVINOS}

uma degeneração hidrópico-vacuolar no epitélio dos túbulos contornados distais dos rins (Górniak et al., 1987), com forte picnose nuclear e o citoplasma torna-se quase imperceptível (Tokarnia et al., 1991)

O diagnóstico de intoxicação por $P$. marcgravii em bovinos deve basear-se no maior número possível de dados. A lesão microscópica nos rins, quando presente é de grande valor, porém ela não é patognomônica (Tokarnia et al., 2000). Não se recomenda qualquer tratamento, em razão da evolução superaguda da intoxicação. Recomenda-se deixar o animal sossegado movimentandoo o mínimo necessário (Freitas et al., 1995; Tokarnia et al., 2000). Ainda não há tratamento satisfatório para a intoxicação de ruminantes pela $P$. marcgravii. Experimentalmente, bons resultados foram obtidos em ratos com a administração de xilazina, hidrato de cloral e acetamida, porém estas substâncias não foram ainda comprovadas na reversão da intoxicação em bovinos (Tokarnia et al., 2000).

Os métodos profiláticos conhecidos são cercar bem as áreas infestadas, matas e as capoeiras onde existir a planta, ou erradicar a planta dos locais aos quais o gado tem acesso. É importante o cuidado com pastos recém-formados, inspecionando-os e arrancando a erva-de-rato e/ou combatendo-a com herbicidas antes de colocar os animais no pasto (Freitas et al., 1995; Barbosa et al., 2003).

Provavelmente uma solução para a intoxicação pela $P$. marcgravii esteja no desenvolvimento de tolerância dos animais à intoxicação. Neste sentido, foi realizada modificação genética em uma bactéria da microbiota ruminal, Butyrivibriofibrisolvens, tornando-a capaz de degradar o fluoracetato (Gregg et al., 1998). Resultados promissores na prevenção da intoxicação por fluoroacetato em animais de laboratório têm sido obtidos pela administração de substâncias que fornecem acetato durante a sua metabolização, porém a administração deve ser feita antes da exposição ao fluoroacetato ou logo no início do período de latência. Os melhores resultados têm sido obtidos com monoacetato de glicerol (monoacetina) (via intramuscular) e acetamina (via oral) (Vickery e Vickery, 1973; Kellerman et al., 1988).

\section{Mascagnia RIGIDA}

Mascagnia rigida (Juss.) Griseb., da família Malpighiaceae, conhecida pelos nomes vulgares de "tingui" e "timbó"; "pelabucho" e "quebra-bucho" (Bahia); "salsa rosa" e "rama-amarela" (Minas Gerais); "suma-branca" e "suma-roxa" (Espírito Santo) (Tokarnia et al., 2000), é um arbusto escandente comum nas regiões secas do país. É encontrada em todo o Nordeste do Brasil, e também em Minas Gerais (Freitas et al., 1995; Kissmann e Groth, 2000; Tokarnia et al., 2000) e Espírito Santo. É uma planta de agreste e do sertão, porém, ocorre nos locais mais frescos (Tokarnia et al., 2000). A ingestão das folhas pelo gado, leva o animal a morte súbita, 24 a 48 horas após a ingestão (Rizzini e Mors, 1976; Rizzini e Mors, 1995).

As plantas de Mascagnia são perenes e se reproduzem por sementes. As espécies tóxicas de Mascagnia que ocorrem no Brasil são semi-arbustivas, com ramos em forma de lianas (cipós). Entre as Malpighiáceas, as plantas do gênero Mascagnia se caracterizam por apresentarem inflorescências cujas flores possuem pétalas amarelas, com sépalas contendo oito glândulas e frutos esquizocárpicos, separando-se em três samarídeos. As sâmaras apresentam alas laterais livres entre si ou unidas, contínuas e inteiras ou marginadas ou bilobadas no ápice, com núcleos seminíferos contendo uma única semente. O sistema radicular é bastante desenvolvido, visto que se desenvolvem bem em regiões secas e rebrotam facilmente depois de roçadas (Kissmann e Groth, 2000). As folhas são elípticas, opostas, coriáceas, com nervação acentuada dorsalmente, a inflorescência é um cacho axiliar e terminal, com flores pequenas e amareladas. A planta se propaga também através de rizomas (Figueiredo e 
Santos, 2001).

Sob condições naturais, a intoxicação por M. rigida ocorre principalmente em bovinos (Tokarnia et al., 1961), mas tem sido descrita também em caprinos (Oliveira et al., 1978). Não há registros de que a planta afete eqüinos, e relata-se que os ovinos são mais resistentes que os bovinos (Freitas et al., 1995).

O extrato preparado das folhas secas de $M$. rigida foi administrado experimentalmente em ratos, camundongos, porcos de guiné, hamsters e coelhos, sendo que os coelhos representaram o melhor modelo animal para estudos dos efeitos tóxicos de M. rigida (Batatinha et al., 1988). Os bovinos ingerem as folhas de $M$. rigida indiscriminadamente, em qualquer época do ano, porém, segundo históricos em Minas Gerais e Espírito Santo, a intoxicação ocorreria mais na época da seca (sobretudo agosto e setembro), quando a planta brota (Tokarnia et al., 2000).

Em condições de mata, os ramos de Mascagnia estendem-se sobre a copa das árvores, ficando fora do alcance do gado. Os bovinos ingerem as folhas dessa trepadeira quando esta é encontrada em capoeiras, onde a vegetação é baixa e em locais de desmatamento recente, onde ocorre intensa brotação da planta, ou quando ocorre a dispersão de sementes formando novos povoamentos de plantas (Gava et al., 1997).

O princípio tóxico para alguns autores é desconhecido (Tokarnia et al.,2000), porém outros citam o princípio ativo como sendo uma saponina (Freitas et al., 1995) e, para outros, um glicosídeo digitálico (Figueiredo e Santos, 2001). Tokarnia et al. (1961) realizaram uma série de experimentos com bovinos, nos quais a menor dose única capaz de causar a morte foi de 50 gramas de planta para cada quilograma de peso vivo do animal $(50 \mathrm{~g} / \mathrm{kg})$, porém Santos et al. (1975) realizou experimentos com bovinos, onde foram administrados, diariamente, por via oral, 4 gramas de $M$. rigida por quilograma de peso vivo do animal (4 g/ $/ \mathrm{kg})$, nas fases da planta: adulta, com folhas, flores e frutos; fase de brotação; e planta seca, obtendo óbitos em todos os grupos testados.

Os sintomas evidentes da intoxicação por $M$. rigida são falta de apetite, depressão, andar cambaleante, tremores musculares e, às vezes, convulsões. A morte sobrevém após uma evolução aguda (Freitas et al., 1995). Nos experimentos de Santos et al. (1975) observou-se presença de muco nas fezes, polaquiúria e albuminúria apenas em alguns animais, enquanto os valores séricos da transaminase glutâmica oxalacética e fosfatase alcalina tiveram seus índices aumentados. As dosagens de cálcio e fósforo no soro, bem como a contagem de hemácias, hemoglobina e volume globular não se modificaram. As mortes ocorreram de maneira súbita, sendo sempre precedidas por queda, tremores musculares e movimentos de pedalagem. Durante a necropsia, foi encontrado muco na porção final do intestino grosso. Os exames histopatológicos apresentaram: no coração, áreas de dissociação de fibras musculares e de degeneração turva; nos rins, áreas de degeneração hidrópica, e nefrite; na bexiga, degeneração vacuolar no epitélio de transição; no intestino grosso, enterite catarral e hiperplasia de células caliciformes; no fígado, hiperemia, áreas de degeneração turva, necrose de coagulação, focos de degeneração gordurosa e dilatação de capilares sinusóides (Santos et al., 1975).

Histologicamente, em casos naturais e experimentais, pode-se constatar áreas focais de infiltrados linfo-histiocitários no miocárdio, edema e processos degenerativos nas fibras musculares do coração e degeneração hidrópico-vacuolar associada à picnose nuclear das células epiteliais dos túbulos contornados distais nos rins. Perante o quadro de morte súbita, onde os achados de necropsia são pouco específicos, a lesão renal, quando presente tem muito valor no diagnóstico. Não se conhece tratamento 


\section{PLANTASTÓXICAS CAUSADORAS DE MORTE SÚBITA EM BOVINOS}

para esse tipo de intoxicação. Recomendase deixar o animal intoxicado em repouso. A profilaxia consiste em movimentar com cuidado os bovinos que estavam em pasto invadido pela planta, para outro pasto onde não exista $M$. rigida. Na tentativa de erradicação da planta deve ser levado em consideração que o seu sistema radicular é bem desenvolvido. Há relatos de proprietários, no Espírito Santo, que obtiveram sucesso pulverizando os tocos da planta cortada com foice a 10 centímetros do solo, com solução aquosa de Tordon 101 a 4\% (Tokarnia et al., 2000).

\section{TETRAPTERYS ACUTIFOLIA}

Tetrapterys acutifolia Cav. é um cipó ou arbusto escandente da família Malpighiaceae, conhecida no Estado de Minas Gerais como "cipó-ruão" e "cipó-preto", sendo uma planta tóxica importante em algumas áreas da região Sudeste. Tetrapterys spp são plantas restritas à região Sudeste do Brasil. Tetrapterys acutifolia ocorre em extensas áreas do Estado de Minas Gerais e abrange alguns municípios do Estado do Espírito Santo (Tokarnia et al., 2000). Nas composições descritas na Flora Brasiliensis verifica-se que espécies de Tetrapterys estão classificadas entre pseudo-arbustos e trepadeiras (Hoehne, 1939). Tetrapterys acutifolia é uma planta viçosa, com folhas de coloração verde bem evidente, com inflorescência sob a forma de panícula, com flores amarelas que quando frutificam adquirem coloração marrom-avermelhada. Sob condições naturais, intoxicações por Tetrapterys spp só ocorrem em bovinos. Experimentalmente, além de bovinos têm-se usado também coelhos e os relatos de intoxicação ocorrem mais na época da seca, de agosto a outubro, quando o gado ingere a brotação da planta (Tokarnia et al., 2000).

Os quadros clínicos de intoxicação por T. acutifolia já foram constatados em diversos municípios dos Estados do Rio de Janeiro, São Paulo, Minas Gerais e Espírito Santo, os casos ocorrem durante todo o ano e a morbidade varia de 6 a $28 \%$, com letalidade próxima a 100\%(Riet-Correa et al., 2001). O quadro clínico de cardiomiopatia causado por Tetrapterys spp. tem sido observado, também nos casos de intoxicação por Ateleia glazioviana, e no sul da África, em ruminantes que consomem plantas da família Rubiaceae (Pachystigma spp, Pavetta spp e Fadogia monticola), que também causam fibrose cardíaca. Fourie et al. (1995) comprovou que o precipitado etanólico de Pavetta harborii causa os mesmos sinais clínicos e lesões. Uma substância denominada pavetamine contida no precipitado etanólico de Pavetta harborii foi identificada como seu princípio ativo (Schultz et al., 2004). A semelhança das manifestações clínicas e lesões causadas pelas plantas da família Rubiaceae presentes no sul da África e as causadas por Tetrapterys spp e Ateleia glazioviana sugere que estas últimas possam conter o mesmo princípio ativo da Pavetta harborii. Esta semelhança é sugerida também pelo fato de que tanto o princípio ativo das plantas do sul da África quanto o princípio ativo de A.glazioviana não afetam animais de laboratório quando administradas pela via oral e são termoestáveis a $100^{\circ} \mathrm{C}$ (Leite et al., 2002).

Experimentalmente comprovou-se que a brotação da planta é responsável pela intoxicação natural. A morte dos animais e as típicas lesões cardíacas puderam ser reproduzidas com os brotos frescos nas seguintes dosagens por via oral: $5 \mathrm{~g} / \mathrm{kg} / \mathrm{dia}$ durante 60 dias; $10 \mathrm{~g} / \mathrm{kg} /$ dia durante 13 a 41 dias e $20 \mathrm{~g} / \mathrm{kg} /$ dia durante 10 dias (Tokarnia et al., 2000).

As intoxicações por Tetrapterys spp causam sinais clínicos relacionados à insuficiência cardíaca, como veia jugular ingurgitada, pulso venoso positivo, edema da região da barbela e arritmia cardíaca. A evolução é subaguda a crônica, podendo ocorrer a "morte súbita" quando os animais são forçados a se movimentar. Outros sinais clínicos observados são edema esternal ("peito inchado", dificuldade de locomoção, 
letargia, fraqueza, anorexia, tremores musculares, leve dispnéia e fezes ressequidas. Ocorrem, também, abortos e nascimento de bezerros fracos que logo morrem (Tokarnia et al., 1989). As intoxicações por Tetrapterys spp causam fibrose cardíaca levando os animais a morrerem subitamente (Bennets et al., 1948; Tokarnia et al., 1989; Gava et al., 2001).

À necropsia, as lesões mais importantes são encontradas no coração sob forma de áreas claras que podem ser vistas através do epicárdio; ao corte, observa-se manchas e feixes esbranquiçados, muito nítidos, ocupando boa parte do miocárdio, que às vezes está endurecido. Há alterações secundárias como edemas e derrames serosos em cavidades. O fígado apresenta, em quase todos os casos, alterações que se caracterizam por lobulação nítida, aspecto de noz-moscada e às vezes está mais firme do que o normal. Os principais achados histológicos restringemse ao coração e fígado. No coração são observados edema intracelular, lise de fibras, edema extracelular, aumento da eosinofilia do citoplasma de grupos de fibras cardíacas (necrose incipiente), apoptose, infiltrado inflamatório, fibrose e atrofia de fibras cardíacas. No fígado há congestão, edema dos espaços de Disse, tumefação, vacuolização e lise dos hepatócitos e fibrose. O quadro clínico é bastante característico, principalmente quando há o edema esternal, porém em animais mais jovens os sinais são menos específicos, sendo que o mais importante para fechar o diagnóstico são as alterações macro e microscópicas do coração, associados aos dados epidemiológicos. Também não se conhece tratamento específico para as intoxicações por Tetrapterys spp. Deve-se recomendar a retirada do rebanho do pasto logo quando ocorrer os primeiros casos. Os animais doentes devem ser deixados em repouso à sombra e bem tratados. A profilaxia consiste na erradicação da planta dos pastos e no isolamento das áreas de mata nativa, capoeiras e locais onde exista a planta (Tokarnia et al., 2000).

\section{OXYPETALUMBANKSII}

Tem-se na família Asclepiadaceae mais de 2.000 espécies trepadeiras, arbustivas e herbáceas que se apresentam em quase todas as regiões do mundo, excluídas somente das regiões Árticas e Antárticas (Hoehne, 1939). Oxypetalum banksii é vulgarmente conhecido como "erva de rato", "timbó", "paininha" (Tokarnia et al., 2000), "cipóde-leite", "cipó-de-seda", "cipó-dasfeiticeiras", "cipó-de-cachorras", e tem ocorrência registrada nas regiões Nordeste, Sudeste e Sul do Brasil, desde o nível do mar até 1.800 metros de altitude. Ocorrem cerca de 100 espécies de Oxypetalum no mundo, a espécie mais citada no Brasil é o Oxypetalum banksii Roen. e Schult., a qual é considerada tóxica para o gado bovino. É provável que outras espécies também apresentem compostos tóxicos, mas faltam estudos detalhados a esse respeito (Kissmann e Groth, 2000).

À primeira vista, o Brasil é rico em plantas tóxicas, uma vez que a crendice popular acusa muitas plantas de serem tóxicas, porém sem nenhuma comprovação da mesma. Um exemplo típico é o encontrado em Oxypetalum banksii, invariavelmente apontado como muito venenoso, sendo a planta lactescente mais acusada de causar mortes em bovinos e, entretanto, comprovadamente inócuo através da experimentação(Tokarnia et al., 1967; Rizzini e Mors, 1995). Tokarnia et al. (1967) escolheram plantas, sobre as quais havia dados bibliográficos, informações verbais ou observações próprias, indicando a sua eventual toxicidade, mas sobre as quais faltavam os necessários dados experimentais. Os experimentos consistiram na administração em bovinos, por via oral, de diversas partes das diferentes plantas. Os resultados foram inteiramente negativos para várias espécies de plantas, dentre elas, O. banksii (partes aéreas). O mesmo já tinha sido observado por Rizzini e Mors (1995), porém Kissmann e Groth (2000) afirmam que o O. banksii é 


\section{PLANTASTÓXICAS CAUSADORAS DE MORTE SÚBITA EM BOVINOS}

tóxico para bovinos. As doses administradas em bovinos por Tokarnia et al. (1967), variaram de 1,8 a 12 gramas das partes aéreas da planta por quilograma de peso vivo do animal.

O gênero Oxypetalum se caracteriza por apresentar corola suplementar, denominada de corona, apêndice estigmático longamente rostreado e excerto, geralmente bífido ou plurilobulado, estigma de base nunca bulbiforme. É uma planta perene reproduzida por sementes, desenvolve-se de forma volúvel, sobre o solo ou sobre outra vegetação. O caule é muito ramificado, fino, com ramos novos alvos-pilosos. As folhas são opostas, curto-pecioladas, de limbo ovalado ou oval-oblongo, com até 12 centímetros de comprimento por 6 centímetros de largura, de base cordada ou auriculada e ápice acuminado, limbo tomentoso ou pubescente, especialmente sobre as nervuras. As inflorescências são corimbiforme, com pedúnculos de até cinco centímetros de comprimento, pubescentes, suportando 2-12 flores. As flores são pediceladas, com cálice gamossépalo, com sépalas linear-lanceoladas, com 3-4 milímetro de comprimento por 1-1,5 milímetro de largura, externamente pubescentes. A corola é rotácea, de lobos fortemente reflexos na antese, linear-lanceolados com 1-1,2 centímetros de comprimento por 2-3 milímetros de largura, externamente pubescentes, de coloração amarela ou verde-amarelada com base arroxeada, ginostégio séssil ou estipitado, anteras com apêndices membranáceos excertos, polínios sigmóides ou subsigmóides, afilados na extremidade inferior. Os frutos são folículos solitários ou difolículos, fusiformes, acuminados, estriados longitudinalmente, com até oito centímetros de comprimento por 15 milímetro de largura acima da base, de parede sub-coriácea, castanha na maturação, abrindo-se longitudinalmente para liberar as sementes, inseridas com as comas voltadas para o ápice do fruto. As sementes ovaladas ou subovaladas, com 4,5-6 milímetros de comprimento por 1,3-2,5 milímetros de largura, aladas, formando um conjunto achatado de base arredondada e ápice subagudo de coloração castanha, longa coma sedosa branca, com muitos filamentos com cercas de dois centímetros de comprimento, que se desprende facilmente. As sementes com a colma assemelham-se muito às de Asclepias curassavica, também uma Asclepiadácea (Kissmann e Groth, 2000).

\section{CONCLUSÃO}

De acordo com vários autores é desconhecido o princípio ativo de muitas espécies de plantas descritas no Brasil, e esse conhecimento é necessário para desenvolver técnicas mais eficientes de controle das intoxicações por plantas. O método mais eficaz para se evitar mortes dos animais por plantas é o estabelecimento de um diagnóstico preciso dos casos de intoxicação e a prevenção de novos casos. Deve-se então atentar para uma boa anamnese, fazer um levantamento do histórico de cada caso de intoxicação, levando-se em consideração as características da região. É necessária uma identificação a campo da planta, realizando-se uma inspeção na área suspeita, para obter a certificação da ocorrência desta na região. Também é muito importante verificar os indícios de intoxicação animal como as marcas de pegadas ao redor da planta, folhas comidas, plantas pisoteadas, e até mesmo, ossada de animais mortos nas proximidades das plantas. Sempre que possível deve-se realizar o exame necroscópico dos animais que vierem a óbito.

Na região Sul Capixaba tem-se observado que os animais geralmente ingerem plantas tóxicas quando esses têm acesso a áreas de mata, ou áreas próximas destas, onde existam exemplares da planta ou onde ela possa lançar ramos ou sementes, dispersando assim novas plantas nos pastos próximos à sua área de ocorrência natural. Os problemas de intoxicação por plantas ocorrem eventualmente em qualquer época 
do ano e agravam-se na época da seca ou após queimadas, quando a falta de alimentos obriga os animais a ingerir essas plantas.

Apesar dos inúmeros estudos sobre o assunto plantas tóxicas, ainda existem muitas dúvidas a respeito do mesmo e algumas informações são insuficientes, contraditórias ou mesmo inexistentes. Essas observações são evidenciadas quando se compara experiências pessoais e relatos de produtores rurais com alguns dados da literatura. Por exemplo, Tokarnia et al. (2000) relatam que a intoxicação por Tetrapterys acutifolia ocorre mais na época da brotação da planta, porém nos casos acompanhados na Região Sul Capixaba um grande número de animais ingeriram a planta quando esta estava em fase de floração, em plena fase reprodutiva. Os animais ingeriram T. acutifolia quando tiveram acesso a áreas de mata, onde existiam os exemplares da planta. Em relação ao Oxypetalum banksii, existem estudos sobre suas características botânicas, porém há carência de dados mais detalhados a respeito das suas potencialidades tóxicas.

\section{BIBLIOGRAFIA}

Barbosa, J.D, C.M.C. Oliveira, C.H. Tokarnia and F. Riet-Correa. 2003. Comparação da sensibilidade de bovinos e búfalos à intoxicação por Palicourea marcgravii (Rubiaceae). Pesqui. Vet. Bras., 23: 167-172.

Batatinha, M.J., H.S. Spinosa and M.M. Bernardi. 1988. Toxic effects of Mascagnia rigida in laboratory animals. Vet. Human Toxicol., 30: 259.

Bennets, H.W., A.B. Beck and R. Harley. 1948. The pathogenesis of "falling disease". Austr. Vet. J., 24: 237-244.

Bertinato, A.E. 1979. Plantas tóxicas no planalto mineiro. O Ruralista, 17: 9.

Costa, M.V., E.F. Nascimento, J.M. Pessoa e W.R. Costa. 1984. Lesões em bovinos intoxicados pela Palicourea marcgravii st. Hil. Arq. Bras. Med. Vet. Zootecn., 36: 571-580.

Couceiro, J.E.M., Silva, A.C.C. and Silva, J.A.
Apesar de Tokarnia et al. (1967) e Rizzini e Mors (1995), através de dados experimentais, demonstrarem resultados negativos para a toxidez do $O$. banksii, Kissmann e Groth (2000), assim como os relatos de alguns produtores rurais da região Sul do Estado do Espírito Santo afirmam que o O. banksii é tóxico para bovinos. Existem relatos (dados não publicados) de possíveis intoxicações com O. banksii de modo acidental. Por se tratar de um vegetal volúvel que se desenvolve juntamente com o capim é constantemente cortado com a forrageira e oferecido aos animais. No entanto, devido à ausência de estudos mais apurados sobre a intoxicação por $O$. banksii, e à dualidade sobre seu potencial tóxico, ainda não se tem descrição dos sinais clínicos e alterações patológicas que esta planta provoca nos animais. Dessa forma fica evidente a necessidade de estudos mais acurados a respeito dos casos de intoxicação por plantas em nosso país, sendo este trabalho pioneiro no levantamento das principais plantas tóxicas causadoras de morte súbita na Região Sul do Estado do Espírito Santo.

1976. Observações e ensaios sobre a alegada intoxicação de bovinos por plantas, no Estado de Pernambuco. In: XV Congresso Brasileiro de Medicina Veterinária, Rio de Janeiro. Anais, SBMV. Rio de Janeiro. pp: 45-46.

Döbereiner, J. and C.H. Tokarnia. 1959. Intoxicação de bovinos pela "erva de rato" (Palicourea macgravii) no Vale do Itapicuru, Maranhão. Arq. Inst. Biol. Anim., 2: 83-91.

Döbereiner, J., C.H. Tokarnia and M.F. Silva. 1983. Intoxicação por Arrabidaea bilabiata (Bignoniaceae) em bovinos na região Amazônica do Brasil. Pesqui. Vet. Bras., 3: 17-24.

Fernandes, N.S. and R. Macruz. 1964. Toxicidade da "corona", Mascagnia pubiflora (Juss.) Griseb. (Malpighiaceae). Arq. Inst. Biol. Anim., 31: 1-4.

Figueiredo, L. and H. Santos. 2001. Catálogo das principais plantas tóxicas do Estado da Bahia. 


\section{PLANTASTÓXICAS CAUSADORAS DE MORTE SÚBITA EM BOVINOS}

Agência Estadual de Defesa Agropecuária da Bahia-ADAB. Salvador, BA. $32 \mathrm{p}$.

Fourie, N., G.L. Erasmus, R.A. Schultz and L. Prozesky. 1995. Isolation of the toxin responsible for gousiekte, a plant-induced cardiomyopathy of ruminants in southern Africa. J. Vet. Res., 62: 77-87.

Freitas, S.P., J.F.S. Silva and L.R. Ferreira. 1995. Principais plantas tóxicas para herbívoros. UFV. Viçosa, MG. 32 p.

Gava, A., C.S.L. Barros, C. Pilati, S.S. Barros and A.M. Mori. 2001. Intoxicação por Ateleia glazioviana (Leg. Papilionoideae) em bovinos. Pesqui. Vet. Bras., 21: 49-59.

Gava, R., J. Cristani, J.V. Branco, D.S. Neve, A.J. Mondadori and R.S. Souza. 1997. Mortes súbitas em bovinos causadas pela ingestão de Mascagnia sp (Malpighiaceae) no estado de Santa Catarina. Pesqui. Vet. Bras., 18: 16-20.

Górniak, S.L. 1988. Intoxicação por Palicourea marcgravii: uma abordagem experimental. Tese (Doutorado). Universidade de São Paulo. USP. São Paulo, SP. 99 p.

Górniak, S.L., Palermo-Neto, J. and Spinosa, H.S. 1987. Plantas tóxicas de interesse agropecuário: Palicourea marcgravii. Hora Vet., 39: 40-44.

Gregg, K., B. Hamdorf, K. Henderson, J. Kopecny and C. Wong. 1998. Genetically modified ruminal bacteria protect sheep from fluoroacetate poisoning. Appl. Environm. Microbiol., 64:34963498.

Hall, R.J. 1972. The distribuition of organic fluorine in some toxic tropical plants. New Phytol., 71: 855-871.

Hoehne, F.C. 1939. Plantas e substâncias vegetais tóxicas e medicinais. Graphicars. São Paulo, SP. 355 p.

Kellerman, T.S., J.A.W. Coetzer and T.W. Naúde. 1988. Plant poisoning and mycotoxicoses of livestock in Southern Africa. Oxford University Press. Cape Town. p.83-130.

Kissmann, K.G. and D. Groth. 2000. Plantas infestantes e nocivas. Tomo III. $2^{\mathrm{a}}$ ed. BASF. São Paulo, SP. 726 p.

Leite, L.G., F. Riet-Correa, R.M.T. Medeiros, A. Piacenti, M. Aragão and S. Shons. 2002. Susceptibilidade de animais de laboratório à intoxicação experimental por Ateleia glazioviana (Leg.Papilionoideae). Pesqui. Vet. Bras., 22: 73-78.
Mello, E.M.M. and J.S. Fernandes. 1941. Contribuição ao estudo de plantas tóxicas brasileiras. Serviço de Informação AgrícolaMinistério da Agricultura. Rio de Janeiro, RJ. 106 p.

Moraes, R.L.F. 1993. Comprovação química e biológica da presença de monofluoracetato nas folhas de Palicourea marcgravii st. Hil.. Tese (Doutorado). Universidade de São Paulo. USP. São Paulo, SP. 83 p.

Oliveira, M.M. 1963. Chomatographic isolation of monofluoracetic acid from Palicourea macgravii st. Hil. Experientia, 19: 586.

Oliveira, A.C., G.C. Oliveira, A.A. Paraguassu and L.M.G.M. Freire. 1978. Intoxicação por um "tingui" (Mascagnia rigida Griseb.) em caprinos na Bahia. In:XVI Congresso Brasileiro de Medicina Veterinária, Salvador. Anais. SBMV. p. 45-46.

Pacheco, G. and V. Carneiro. 1932. Estudos experimentais sobre plantas tóxicas. Intoxicação dos animais pela "erva de rato da mata" Palicourea marcgravii st. Hil. Rev. Soc. Paulista Med. Vet., 2: 23-46.

Peixoto, P.V., C.H. Tokarnia, J. Döbereiner, J. and C.S. Peixoto. 1987. Intoxicação experimental por Palicourea marcgravii (Rubiaceae) em coelhos. Pesqui. Vet. Bras., 7: 117-129.

Riet-Correa, F. and R.M.T. Medeiros. 2000. Intoxicações por plantas em ruminantes no Brasil e no Uruguai: importância econômica, controle e riscos para a saúde pública. Pesqui. Vet. Bras., 21: 38-42.

Riet-Correa, F., M.C. Mendez and A.L. Schild. 1993. Intoxicações por plantas e micotoxicoses em animais domésticos. Editorial Hemisfério Sul. Montevideo. $340 \mathrm{p}$.

Riet-Correa, F., A.L. Schild, M.C. Mendez and R.A.A. Lemos. 2001. Doenças de ruminantes e eqüinos. Vol.2. Editora Varela. São Paulo, SP. $573 \mathrm{p}$.

Rizzini, C.T. and W.B. Mors. 1976. Botânica econômica brasileira. Editora da Universidade de São Paulo. São Paulo, SP. 207 p.

Rizzini, C.T. and W.B. Mors. 1995. Botânica econômica brasileira. 2 ed. Editora Âmbito Cultural. Rio de Janeiro, RJ. 241 p.

Santos, H.L., M.B. Ferri and W.R. D'Assumpção. 1975. Levantamento de plantas tóxicas para bovinos suspeitas de serem tóxicas no estado de Minas Gerais. EPAMIG. Belo Horizonte, 


\section{CARVALHO, NUNES, BRAGANÇA E PORFÍRIO}

MG. 69 p.

Schultz, R.A., N. Fourie, M.L. Bode, K.M. Basson, L. Labuschagne, R. Vleggaar and C. Medlen. 2004. Pavetamine: an inhibitor of protein synthesis in the heart. In: Acamovic, T., Stewart, C.S. e Pennycott, T.W. Poisonous plants e related toxins. CAB, Willingford, p. 408-411.

Schvartsman, S. 1979. Plantas venenosas. Sarvier. São Paulo, SP. 176 p.

Schvartsman, S. 1992. Plantas venenosas e animais peçonhentos. Sarvier. São Paulo, SP. $288 \mathrm{p}$.

Sherley, M. 2004. The traditional categories of fluoroacetate poisoning signs e symptoms belie substantial underlying similarities. Toxicol. Letters, 151: 399-406.

Tokarnia, C.H., C.F.C. Canella and J. Döbereiner. 1961. Intoxicação por um "tingui" (Mascagnia rigida) em bovinos no Nordeste do Brasil. Arq. Inst. Biol. Anim., 4: 203-215.

Tokarnia, C.H., C.F.C. Canella and J. Döbereiner. 1967. Experimentos com plantas suspeitas de serem tóxicas realizados em bovinos no Estado do Rio de Janeiro, que resultaram netativos ou em pertubações leves passageiras. Pesqui. Agropec. Bras., 2: 343-351.

Tokarnia, C.H., E.R. Costa, J.D. Barbosa, A.G. Armién and P.V. Peixoto. 1993. Intoxicação por Palicourea marcgravii (Rubiaceae) em eqüinos. Pesqui. Vet. Bras., 13: 67-72.

Tokarnia, C.H. and J. Döbereiner. 1981. Intoxicação por Arrabidaea japurensis em bovinos em Roraima. Pesqui. Vet. Bras., 1: 7-17.

Tokarnia, C.H. and J. Döbereiner. 1982. Intoxicação por Palicourea juruana (Rubiaceae) em bovinos e coelhos. Pesqui. Vet. Bras., 2: 17-26.

Tokarnia, C.H. and J. Döbereiner. 1986. Intoxicação por Palicourea marcgravii (Rubiaceae) em bovinos no Brasil. Pesqui. Vet. Bras., 6: 73-92.

Tokarnia, C.H., J. Döbereiner, C.F.C. Canella and J.D. Guimarães. 1969. Intoxicação experimental por Pseudocalymma elegans (Vell.) Kuhlm. em bovinos. Pesqui. Agropec. Bras., 4: 195204.

Tokarnia, C.H., J. Döbereiner, J.E.M. Couceiro and A.C.C. Silva. 1983. Intoxicação por Palicourea aeneofusca (Rubiaceae), a causa de "mortes súbitas" em bovinos na Zona da Mata de Pernambuco. Pesqui. Vet. Bras., 3: 75-79.

Tokarnia, C.H., J. Döbereiner and P.V. Peixoto. 1985. Intoxicação por Mascagnia aff. rigida (Malpighiaceae) em bovinos no Norte do Espírito Santo. Pesqui. Vet. Bras., 5: 77-91.

Tokarnia, C.H., J. Döbereiner and P.V. Peixoto. 1994. Aspectos clínico-patológicos complementares da intoxicação por algumas plantas tóxicas brasileiras. Pesqui. Vet. Bras., 14: 111-122.

Tokarnia, C.H., J. Döbereiner and P.V. Peixoto. 2000. Plantas tóxicas do Brasil. Editora Helianthus. Rio de Janeiro, RJ. 310 p.

Tokarnia, C.H., J. Döbereiner and M.F. Silva. 1979. Plantas tóxicas da Amazônia a bovinos e outros herbívoros. INPA. Manaus, AM. 95 p.

Tokarnia, C.H., J. Döbereiner and M.F. Silva. 1981. Intoxicação por Palicourea grandiflora (Rubiaceae) em bovinos no Território de Rondônia. Pesqui. Vet. Bras., 1: 85-94.

Tokarnia, C.H., P.V. Peixoto and J. Döbereiner. 1986. Intoxicação experimental por Palicourea marcgravii (Rubiaceae) em ovinos. Pesqui. Vet. Bras., 6: 121-131.

Tokarnia, C.H., P.V. Peixoto and J. Döbereiner. 1991. Intoxicação experimental por Palicourea marcgravii (Rubiaceae) em caprinos. Pesqui. Vet. Bras., 11: 65-70.

Tokarnia, C.H., P.V. Peixoto, J. Döbereiner, L.B. Consorte and A. Gava. 1989. Tetrapterys spp (Malpighiaceae), a causa de mortandades em bovinos caracterizadas por alterações cardíacas. Pesqui. Vet. Bras., 9: 23-44.

Vickery, B. and M.L. Vickery. 1973. Toxicity for livestock of organofluorine compounds present in Dichapetalum plant species. Vet. Bull., 43: 537. 